University of Nebraska - Lincoln

DigitalCommons@University of Nebraska - Lincoln

Faculty Publications in Educational

Administration

Educational Administration, Department of

2020

\title{
Addressing Students' Mental Health Needs in Faculty-Led Study Abroad Courses
}

Elizabeth Niehaus

Angela Bryan

Matthew J. Nelson

Kaleb Briscoe

Follow this and additional works at: https://digitalcommons.unl.edu/cehsedadfacpub

Part of the Counseling Psychology Commons, Educational Administration and Supervision Commons, Industrial and Organizational Psychology Commons, and the School Psychology Commons

This Article is brought to you for free and open access by the Educational Administration, Department of at DigitalCommons@University of Nebraska - Lincoln. It has been accepted for inclusion in Faculty Publications in Educational Administration by an authorized administrator of DigitalCommons@University of Nebraska - Lincoln. 


\title{
Addressing Students' Mental Health Needs in Faculty-Led Study Abroad Courses
}

\author{
Elizabeth Niehaus, Angela Bryan, \\ Matthew J. Nelson, and Kaleb Briscoe \\ Educational Administration, University of Nebraska - Lincoln, \\ Lincoln, Nebraska, USA
}

\begin{abstract}
The increased enrollment of students with mental health needs in U.S. higher education, paired with increasing emphasis on study abroad participation has led campus mental health professionals to consider how their services might extend to serve students with mental health needs who are studying abroad. When it comes to faculty led courses, instructors can play a key role in providing on-the-ground support for students experiencing mental health challenges. The findings from this study provide key insights that college mental health professionals can use to better understand and support these instructors as they serve on the front lines of addressing students' mental health needs while they are away from campus. In particular, our findings point to key ways that college mental health professionals can partner with education abroad offices to provide effective pre-departure training and in-country support for faculty instructors.
\end{abstract}

Keywords- Study abroad; off-campus support; college faculty

The issue of college students' mental health has become increasingly important in recent years (Bathke \& Kim, 2016; Holm-Hadulla \& Koutsoukou- Argyraki, 2015; Prince, 2015). As noted by Prince

Published in Journal of College Student Psychotherapy 2020

DOI: $10.1080 / 87568225.2020 .1760160$

Copyright (C) 2020 Taylor \& Francis. Used by permission. 
(2015), the number of college students experiencing mental health challenges, as well as the severity of these challenges, has increased in the past decade, with anxiety, depression, substance abuse, suicidal ideation, self-harm, and personality disorders becoming more common. There is substantial evidence to support the pre- valence of mental health issues in college: The 2016-2017 Health Minds Study (Healthy Minds Network, 2019) found that 39\% of college students are experiencing a significant mental health issue, and the American College Health Association (American College Health Association (ACHA), 2018) recently found that over $30 \%$ of students reported being diagnosed with or treated for a mental health condition in the previous twelve months.

This rise in mental health concerns in college has coincided with an overall increase in the number of college students studying abroad (Institute of International Education (IIE), 2016). The intersection of these two trends has led to a critical need to examine the mental health issues that can arise during a study abroad experience. One of the few studies addressing the incidence of mental health needs in study abroad students found that $27.7 \%$ of students who studied abroad reported experiencing mental health issues prior to going abroad (Bathke \& Kim, 2016), a number comparable to the ACHA's 2018 findings.

While study abroad experiences can offer unique learning opportunities (Herbst, 2011; Tuma, 2007), they can also be stressful environments for any student (Hunley, 2010). For students with existing mental health challenges, studying abroad can add another layer of stress that can exacerbate and amplify these challenges (Heely, 2005; Prince, 2015). Factors common to the study abroad experience, such as loss or separation from family and friends, the stress of travel, culture shock, cross-cultural adjustment, social or group dynamics, or unforeseen events (e.g., bad news from home), can negatively affect students' mental health (McCabe, 2005). Additionally, students participating in study abroad may use/abuse alcohol - a behavior statistically linked to depression and suicidal ideation (Levy \& Deykin, as cited in Lucas, 2009) - more frequently than in the home country, further compromising their mental wellness. 


\section{Disclosure, institutional liability, and managing risk abroad}

Institutions assume a measure of liability for the physical and mental wellbeing of students in study abroad programs (Rhodes, 2014; Scharman, 2002). Additionally, institutions are bound by federal laws such as FERPA (Family Educational Rights and Privacy Act) and HIPAA (Health Insurance Portability and Accountability Act), which ensure confidentiality of students' educational and health information. According to Prince, DeRomana, Holvey-Bowles, and Hopkins (2006), a fear of violating students' legal rights under FERPA or HIPAA may inhibit or prevent instructors from addressing students' mental health concerns, potentially increasing the likelihood of a mental health crisis while abroad. In the event that a student is harmed while participating in a program, institutions can be charged with negligence, a "failure to exercise the degree of care considered reasonable under the circumstances, resulting in an unintended injury to another party" (Prince et al., 2006, p. 56). For this reason, institutions are encouraged to communicate legal, risk, and liability issues to students prior to departure (Keese \& O'Brien, 2011; Scharman, 2002), as well as to require students to sign assumption of risk and release forms that decrease the institution's liability in the event that a student suffers harm (Adams \& Reinig, 2017; Keese \& O'Brien, 2011; Scharman, 2002).

In addition to risk and release forms, institutions generally also require health information forms that specifically include mental health information. Such forms should inquire if the applicant is currently receiving counseling or treatment for a mental condition, has been diagnosed with specific disorders (e.g., anorexia/bulimia, bipolar disorder, anxiety, etc.), is taking psychotropic medications, or has been suicidal (Adams \& Reinig, 2017). While institutions encourage self-disclosure of mental health concerns, many students are averse to disclosing this information because of the stigma associated with mental illness, or because they simply do not trust that the information will remain confidential (Prince et al., 2006). Bathke and Kim (2016) found that $92 \%$ of students who reported experiencing mental health issues while abroad had experienced issues prior to travel, yet less than half $(45 \%)$ of students reported these issues to institutional administrators. 
Students may also believe that by disclosing mental health issues prior to departure, they will be prevented from participating in the program (Prince et al., 2006). While institutions should collect mental health information forms, the information on these forms cannot be used to make decisions on acceptance or rejection into a program or the institution may be subject to claims of bias under the Americans with Disabilities Act (ADA; Adams \& Reinig, 2017; Morse, Spoltore, \& Galvinhill, 2017). To mitigate the possibility of health forms being improperly used to deny access to study abroad programs, some literature suggests that institutions use interviews with candidates as part of the selection process (Adams \& Reinig, 2017; Scharman, 2002). Through interviews, staff or faculty leaders would be able to identify any potential behavioral issues and "determine if the student is well suited for the program" (Adams \& Reinig, 2017, p. 266). However, even if conducted in an "unbiased manner" (Adams \& Reinig, 2017, p. 266), interviews clearly have the potential to serve as an inadvertent screening mechanism in the same way that medical forms might. To increase the likelihood that students will voluntarily self-disclose mental health challenges and to minimize the risk of ADA violations, Morse et al. (2017) suggest a carefully constructed post-admission health screening process including information about site specific stressors, information about predictable challenges facing all students (e.g., homesickness, culture shock), and a confidential health questionnaire that can lead to further discussion as needed.

Ideally, students should be encouraged to self-disclose mental health needs, so that an accommodation plan can be instituted prior to departure and staff will be able to prepare for and more quickly respond to any related crises while abroad (Prince et al., 2006). In the event that students do not self-disclose, faculty leaders must work closely with administrative units on campus to mitigate potential risks (Rhodes, 2014). A lack of mental health professionals or services in the host country, transportation of medications across national boundaries, and inadequate insurance coverage that may not pay for services in the host country may impact the ability of students to manage mental health conditions while abroad (Prince et al., 2006). Faculty leaders can prepare for these risks by identifying resources needed for students experiencing mental health needs and locating those resources in the host country, working with campus counseling professionals to 
employ appropriate responses or interventions, and developing crisis management plans that clearly detail procedures to follow in the event of an emergency (Prince et al., 2006; Rhodes, 2014).

\section{Faculty leaders' preparation to address students' mental health needs}

The largest growth area in U.S. study abroad is through faculty-led, short-term study abroad (FLSTSA) programs (IIE, 2016). These are generally one- to four- week self-contained courses, led by an individual faculty member with a small group of students (Tuma, 2007). The structure of these courses' places faculty members on the front line of addressing students' mental health needs while abroad, but instructors who do not have adequate preparation and training may struggle to help students who are experiencing the wide array of mental health issues that may arise during study abroad (Bathke \& Kim, 2016).

In order for students to fully benefit from a study abroad experience, faculty leaders of these programs must be adequately prepared to address students' mental health needs while abroad. A review of the literature revealed a primary focus on preparing faculty members to respond to mental health crises, with less discussion regarding preparing students and/or faculty leaders to manage mental health needs while abroad. While the literature did reveal a broad definition of mental health needs, such as culture shock, long-distance relationships, grief, substance abuse, depression, anxiety, schizophrenia, and paranoia (e.g., McCabe, 2005; Prince et al., 2006), there was an emphasis on clinically diagnosed mental disorders and little discussion regarding how to support students with less severe mental health needs. As Hunley (2010) noted, even moderate levels of psychological stress and loneliness experienced during study abroad can adversely affect students' functioning and inhibit their ability to benefit from the experience, so it is important that faculty leaders are prepared to help manage the mental health needs of participants.

Preparing study abroad faculty leaders to address students' mental health needs involves a coordinated effort among a variety of institutional stake- holders. According to Lucas (2009), institutions should work with faculty leaders to establish a comprehensive written policy 
for addressing mental health needs abroad, outlining a clear protocol to manage any crises that may arise. Faculty leaders might also consider utilizing a co-leader, such as a student affairs professional, who may be better trained to support students with mental health needs and can relieve faculty leaders of responsibilities they may not be comfortable handling (Feldman Barr, 2013).

Additionally, a number of scholars and practitioners (e.g., Leggett, 2012; Lucas, 2009; Morse et al., 2017; Prince et al., 2006) recommend that institutions provide faculty members with effective training developed through a partnership between the institutions' study abroad offices and counseling centers. At a minimum, training should focus on identifying mental health needs, learning about resources on-campus and in the host country, and developing strategies to help connect students to those resources (Leggett, 2012). Legal concerns, such as those associated with the ADA, FERPA, and HIPAA, should also be addressed (Morse et al., 2017; Prince et al., 2006). Aside from these and similar recommendations, the literature reveals little regarding the actual nature and extent of faculty leaders' pre-departure preparation for addressing mental health needs abroad.

\section{Purpose and research questions}

As noted above, students' mental health needs are a growing concern in higher education broadly, and in education abroad specifically. As the number of students with mental health needs studying abroad increases, faculty members teaching and traveling with these students will need to be prepared to address mental health issues appropriately. Yet, there is little research on how faculty members are encountering and addressing students' mental health needs in short-term study abroad courses, limiting the ability of college mental health professionals to support faculty members and students in these FLSTSA programs. As such, the purpose of this study was to explore which types of mental health issues instructors in FLSTSA programs are encountering, how instructors are addressing these mental health issues, and what training and preparation they are (and are not) receiving. In particular, we sought to answer the following research questions: 
1. To what extent are faculty instructors being called upon to address students' mental health needs during study abroad courses? To what extent do faculty instructors feel that they should be serving in this role? To what extent do faculty instructors feel prepared to do so?

2. How are faculty members addressing students' mental health needs abroad?

3. What training and support are faculty members receiving prior to teaching abroad? What additional training and support do faculty members need?

\section{Materials and methods}

This study draws on data from a mixed methods study of instructors' approaches to teaching FLSTSA. We employed a sequential explanatory mixed methods approach (Creswell, 2003), where the qualitative data were the main focus of the analysis and the quantitative data provided context and guided the qualitative data collection. The first phase of the study was an online survey of instructors who had taught FLSTSA courses over the prior year. The second phase of the study was a multiple, qualitative case study of individual instructors' experiences addressing students' mental health needs while teaching short-term study abroad courses.

\section{Quantitative phase}

\section{Sampling and data collection}

In the quantitative phase of this study, we first purposefully sampled institutions that had been identified by IIE (2015) as the leading institutions, by institution type, in short-term study abroad programs. We contacted education abroad directors (or similarly situated administrators) and asked them to pass along a survey invitation to faculty. The survey included a variety of questions about participants' prior experience, approach to teaching short- term study abroad, and experiences teaching abroad.

The quantitative sample consisted of 473 faculty members from 72 institutions. Participants were predominantly White (86.4\%), and a 
slight majority were women (52.6\%) and born in the U.S. (50.4\%). Participants covered a wide variety of disciplines and were fairly evenly spread across faculty ranks (non-tenure-track, assistant, associate, and full). Almost half of participants (48.3\%) had taught five or more study abroad courses previously; however, for almost $20 \%$ this was their first time teaching abroad.

\section{Data analysis}

For this particular study, we used a series of questions about the roles that faculty members played during the course (e.g., handling travel logistics, teaching course content, etc.). Participants were asked which roles they played, which they felt prepared to play, and which they thought they should play in teaching abroad. To answer our first research question, we calculated the frequencies for each "role" item, and then computed new variables to reflect the potential disconnect between what participants actually did while teaching abroad with what they felt they should be doing and what they felt prepared to do. We then calculated frequencies for each of those new variables, looking for any roles that faculty members played that they felt that they should not be playing and/or did not feel prepared to play.

\section{Qualitative phase}

Based on the survey results, we focused on how faculty members were encountering students' mental health needs abroad. We employed a multiple case study approach (Merriam, 2007; Stake, 2006) to explore participants' experiences addressing students' mental health needs. Each case was an individual participant, which allowed us to explore individuals' experiences with mental health issues abroad in depth and to compare experiences across multiple cases (Stake, 2006).

\section{Participant selection and data collection}

To explore the phenomenon of addressing students' mental health needs abroad, we identified information-rich cases (Creswell \& Poth, 2018) by first selecting survey respondents who had indicated that they had some role in addressing mental health needs abroad. Within that group we engaged in maximum variation sampling (Creswell \& Poth, 2018) to try to understand a variety of experiences. We 
selected faculty members who said that they did and did not feel prepared to address students' mental health needs, and sought to select participants who had taught in a variety of countries on different continents. We continued to invite additional faculty members to participate until we achieved saturation (Creswell \& Poth, 2018) and were no longer hearing new information from participants. Ultimately, we conducted interviews with thirteen total participants. Of these thirteen participants, seven identified as women and six as men; ten identified as White/Caucasian, two as Asian/Pacific Islander, and one as Hispanic; and nine worked at public universities, two at liberal arts colleges, one at a community college, and one at a historically black college. Participants reflected all tenure-track faculty ranks, along with one non-tenure-track lecturer and one staff member, and included a wide range of disciplines.

All interviews were conducted by the last author to ensure consistency. The interviewer used a semi-structured interview protocol to allow for flexibility in asking participants to describe their experiences teaching abroad and addressing students' mental health needs. Participants were asked to describe what had happened and how they responded, and to describe and evaluate any preparation, training, or support they had, either in-country or from mental health professionals, study abroad offices, or others at their home institution.

\section{Data analysis}

Consistent with multiple case study research, we engaged in withincase followed by cross-case analysis (Stake, 2006). In our within-case analysis we first engaged in descriptive coding (Saldaña, 2016) to organize our data into broad topics discussed in each interview (e.g., mental health triggers, effect on students, etc.). Based on our coding of the interview transcripts, with supporting information from survey responses, we then created case summaries for each participant (Stake, 2006).

In the cross-case analysis we sought to identify similarities and differences across the thirteen participants' experiences. To do this, we first created a visual display (Miles, Huberman, \& Saldaña, 2014) in the form of a chart, with the main topics from each case summary as the columns of the chart and each participant as a row. We then identified four core elements in participants' experiences - the types of mental health needs encountered, participants' responses, the effect 
on other students, and the effect on instructors - and reduced the table to just these elements. We noticed a range of severity/intensity within each of these categories, so we then color coded the table (green for least severe/intense examples, yellow for moderate, red for most severe/intense) in order to visualize how each of these elements (types, responses, and effects) fit together for different participants. For the purpose of this paper, we focus on the results of this analysis related to the types of mental health needs and participants' responses, along with a summary of the convergent and divergent themes in participants' descriptions of the support that they received in responding to students' mental health needs.

\section{Trustworthiness}

To ensure the trustworthiness of our findings, we engaged in member checks (Miles et al., 2014), sending participants statements of their individual case summaries to ensure the accuracy of our interpretation. All participants who responded agreed that our conclusions were accurate. We also used multiple forms of data (e.g., survey data and interviews) to triangulate our data.

\section{Findings}

The purpose of this study was to explore faculty members' experiences addressing students' mental health needs while teaching shortterm courses abroad. In the following sections we present findings from the quantitative and qualitative phases of this sequential mixedmethods study.

\section{Quantitative results: mismatch of experience and preparation}

Contrary to our expectations, we found overall a high level of match between the roles that faculty members played in their study abroad courses, the roles they felt they should play, and the roles they felt prepared to play. One notable exception to this was in faculty members' responses to the role they played in addressing students' mental health needs. Over half of respondents indicated that they had played some role in addressing students' mental health needs (58.1\%), and of those, almost a quarter felt unprepared to do 
so. Interestingly, of the $41.9 \%$ of respondents who did not play a role in addressing students' mental health needs, just over half felt unprepared to do so. Over one-third of participants (34.5\%) responded that faculty instructors should not have a role in addressing students' mental health needs abroad.

\section{Qualitative findings: how instructors respond}

Based on the mismatch between instructors' experience and preparation when it came to addressing students' mental health needs abroad, we explored instructors' experiences further through indepth, qualitative interviews. In the sections below, we describe the insights we gained into how faculty instructors respond to mental health issues that arise during FLSTSA courses, and how they are and are not adequately prepared to do so.

Faculty members responding to mental health challenges

Participants in this study described a range of mental health needs they encountered abroad, including everything from homesickness to ADHD, anxiety, depression, bipolar disorder, and suicidal ideation. Many of these issues, like homesickness and mild anxiety, could be considered typical reactions to international travel, particularly for students without much prior experience; we left it to individual faculty members to define what they saw as a "mental health need." Although many of the issue's participants described would not have been under their purview while teaching on campus, participants noted teaching abroad was fundamentally different from teaching on campus. As Matthew described,

When you're teaching ... short term study abroad, it's usually a more intensive ... community situation ... it's not like you see them for one hour a day and then you don't see them for the rest of the time. You're taking meals with them ... you're going on field trips with them. You're doing a lot.

In the section below, we describe the different ways that participants responded to the variety of mental health issues they encountered, including observation and conversation, involving the home campus, and enlisting the assistance of other students or the host family. 
Observation and conversation. Many participants noted the need for observation and conversation with their students regarding mental health. This was more reactive than proactive, however. Faculty members, including Sarah and Christopher, described "keeping an eye" on students of concern as the study abroad experience unfolded. Given the close quarters and intimate group dynamics of many of these courses, faculty members could often pinpoint students displaying signs that something was awry. With the great deal of time spent together as a group, Matthew shared it was "easy to observe that someone is not coping well or not feeling well or something."

Many participants discussed initiating one-on-one conversations with the student of concern. The conversation usually uncovered some anxiety or homesickness, discussion of medication maintenance, and/ or an offer of assistance from the faculty member. Paul noted:

Well, I talk with the student one-on-one, if I see that they are somewhat detached ... I can kind of get a sense that they are not being part of the collective then I'll talk to them oneon-one and see if it is an issue or a problem and sometimes they will reveal it and sometimes they won't, they'll say everything is fine but it all depends on the individual.

More often than not, the faculty member engaged the student of concern in conversation after observation. It was typically (though not in every situation) the faculty member approaching a student, not the other way around. For example, Matthew shared, "never has a student actually just come to me on their own and said you know I'm having a hard time."

The context of the conversations with students regarding their mental health needs took a variety of forms. In some instances, the student may have been experiencing culture shock and just needed a bit of down time away from the group. For others, faculty members had to remind students to keep up-to-date with their medications. Faculty members working with students experiencing anxiety attempted to preview the upcoming activities, or if needed, modify requirements.

Involving the home campus. A second theme emerging from the case study data relates to more serious mental health needs and the degree to which faculty members sought assistance from mental 
health professionals or others on the home campus. While observation and conversations still occurred with more serious mental health issues, such as bipolar disorder and suicidal ideation, faculty participants described needing to go beyond their own expertise to address these challenges. These action-steps usually included advice-seeking from some combination of the home institution, the parents of the student, and/or a trained medical professional. For instance, two participants detailed their experience responding to students with bipolar disorder. Both described the importance of connecting with the home institution, campus mental health professionals, and parents. Diane shared, "I had her parents' phone number with directions to call or e-mail in case anything was happening ... that was concerning and then I also have the support of on campus." Diane also noted, however, there were limitations of on-campus support: "I know if I have a medical emergency I can work with people on campus, but I am the person who has to deal with this when we are away."

Some participants described addressing students who were thinking of harming or killing themselves. In these instances, faculty members reported directly to their contact on campus: the education abroad office or the dean of students' office. Participants also discussed contacting parents, the home institution, and sometimes even seeking in-country support.

Other responses. Outside of conversations, observations, and reporting back to/involving administrators and mental health professionals on the home campus, participants shared other, less frequent responses. Their other responses included situations such as enlisting the assistance of other students or the host family or changing the living arrangements for the student of concern. For example, Franco shared the calming effect of one such host family. The student referenced was working through anxiety and taking medication for her anxiety, which had flared up given the new environment abroad. The host mother, an elderly woman in her $80 \mathrm{~s}$, provided assistance with this student's needs:

She was able to talk to the student and I think her approach ... her perspective of being an elderly woman who has been around the track a few times. She was able to talk to the student and reassure her and welcome her into her family. 
Similarly, to assist with mild and severe anxiety, Dakota described the importance of modification and previewing with their students: "We try to create a lot of predictability and structure and overkill of previewing what we are doing." This is done in an effort to reduce the likelihood of placing a student in a situation that might activate anxiety, culture shock, nervousness, homesickness, etc. In both cases, such responses showcase the need for quick and creative thinking in order to determine alternate courses of action to best support the students.

\section{Support - what participants had and what they need}

Participants described a number of institutional policies and procedures in place to prepare or assist faculty members with any issues that may arise during their travel abroad. The most commonly cited practice was a pre-departure training session typically offered by study abroad offices or third-party providers administering the program. The topics discussed during these trainings ranged from cultural norms of the host country to basic safety and emergency preparedness (as John described, “crisis response for dummies”). In many of the trainings, there was a discussion of mental health issues, although participants frequently noted that it was limited in scope. While it may be that institutions recognize that general safety issues will arise more frequently than mental health issues abroad, it may also be that institutions prefer that mental health issues be handled by campus mental health professionals with more specialized experience in the field. As John explained,

I think [limited training regarding mental health issues is] because there's only so much we are really capable of or expected to do in situations like that beyond simply recognizing it, reporting them, and instigating a process that involves people at the university who are much more capable than me, you know, diagnosing, treating, and handling those kinds of cases.

By providing training focused on common safety issues and advising faculty leaders to simply recognize, report, and refer students with mental health needs to outside resources, institutions may more effectively prevent crisis situations due to underlying mental health issues. 
Institutional contacts were also identified as an important source of support while abroad. Personnel at an institution's study abroad office or a third-party provider typically provided faculty members with a direct cell phone number, encouraging them to connect with the institution or provider if they have any concerns. At one institution, a 24-hour counseling hotline was available, which allowed both students and faculty members the opportunity to connect to mental health professionals on campus, if needed. Several participants also noted that their institutions utilized incident reports to communicate issues to the home institution. Once received, the incident reports were reviewed by a group of administrators and/or risk management specialists, who analyzed and tracked ongoing situations and advised faculty members on appropriate courses of action.

In addition to contacts at the home institution, participants cited in-country sources of support that aided in responding to students' mental health needs. Faculty members who co-led trips abroad appreciated their faculty co-leaders, who were either able to attend to students' issues or act as classroom facilitator while the participant addressed students' needs. Diane praised her faculty co- leader, who helped a student with autism spectrum disorder "because they were in the same dormitory. He would always make sure that they were going to be checking on him, to make sure that he was at breakfast, to make sure he was on time for the bus, [etc.]," illustrating the benefits of having an additional faculty member accompany the group abroad. In one instance, a student's host mother proved to be a valuable source of support, as she was able to calm the anxious student, give advice, and provide a safe space, minimizing the student's adjustment issues and resulting anxiety. Although a few participants also noted in-country medical personnel as an available support for addressing students' mental health needs, they often did not consider doctors to be effective or did not utilize them for these particular issues, due to host country attitudes toward mental illness.

Although faculty members appreciated the existing supports in place, many participants identified additional practices that would be beneficial in addressing students' mental health needs abroad. Participant responses indicated that a majority of institutions required students to complete a medical history form prior to traveling abroad; however, the type of information collected and the extent to which this information was shared varied across institutions. While some 
institutions collected information about students' mental health issues and shared this information with faculty leaders, others collected this information but did not share it. Other institutions simply did not collect information on mental health needs at all. Those who did not have access to information on students' mental health needs noted that this information may have helped better prepare them to address these issues while abroad. Participants who were provided with this information described the benefits of knowing about potential issues prior to travel. As Stacey stated, $\mathrm{d}$ the form and if there are any health issues that we are uncomfortable dealing with we can seek out campus resources such as counseling services for help with that." Although sharing this information with faculty members helped prepare them to address students' mental health needs abroad, it also seemed to create a desire for some faculty members to be more selective in choosing study abroad participants, which could potentially create legal or ethical issues if pursued.

In addition to prior knowledge of students' mental health needs, several participants wanted more comprehensive training regarding mental health issues, particularly recognizing and addressing these issues in students. Although some institutions offered pre-departure training that included discussion of mental health needs, most participants indicated that this information was superficial. Specifically, participants wanted more in-depth knowledge of mental health issues, discussion of which issues could be more problematic than others, skills or techniques to employ when addressing these issues, and a clear process for handling issues as they arise. Several participants suggested that study abroad offices partner with their institutions' counseling center or mental health professionals, or invite faculty members who have previous experience addressing mental health needs abroad who could advise them regarding these issues. Identification of trained professionals in-country, as well as campus resources to assist with mental health needs abroad, were cited as additional components of comprehensive training regarding students' mental health needs abroad.

While some participants expressed a desire for more comprehensive training regarding mental health needs, others noted that such training may not be helpful. Diane opposed a mandatory, largescale training "for situations that are likely to never occur," instead preferring more in-depth information on the specific mental needs 
of the students accompanying them abroad. Pavel indicated that although their institution provided extensive training regarding mental health needs, it wasn't the issue that most faculty were most concerned about, as matters like "extra stress and terrorism ... [are] much more difficult to manage and to handle than mental health.” In-depth, comprehensive training on mental health needs also did not appeal to John, who noted that such training creates the expectation that a faculty member will be able to effectively manage students' mental health while abroad. According to John, “I don't want to be liable based on whatever training I've been given, to make any kinds of decisions with regard to our students' mental health ... assume."

\section{Discussion and implications}

Mental health issues are a rising concern in study abroad, and with the growing numbers of students participating in short-term, faculty-led study abroad courses, there is a critical need to better understand how faculty members teaching these courses can best support students with mental health needs. In the quantitative phase of this study, we found that over half of our respondents had played a role in addressing mental health needs in their most recent study abroad course and that many felt unprepared when mental health issues arose. The results of this study shed light on faculty members' experiences with students' mental health needs while teaching shortterm study abroad courses, how they are responding, and the ways in which mental health and education abroad professionals on campus can better support faculty instructors abroad.

Many of our participants reflected the findings of Bathke and Kim (2016) and others that students often do not disclose mental health needs prior to studying abroad, and that some students discontinue treatment (including taking necessary medications) while abroad. Our findings provide insight into the complexity of student disclosure of mental health needs prior to studying abroad, at least from the perspective of faculty instructors. On the one hand, there were many examples of faculty instructors being better prepared to help students experiencing mental health issues while abroad because they knew of the potential problems in advance. Stacy, for example, was easily able to adjust course activities for a student experiencing anxiety attacks 
because she knew that this student was on medication for anxiety before they left the U.S. Diane was better able to assist a student with bipolar disorder because she had contact information for the student's parents and additional support on the home campus in case anything happened. On the other hand, some participants directly noted the desire to use this sort of information to potentially exclude certain students from participating in their study abroad course, which reinforces the fear that many students have reported of being screened out because of existing mental health issues (Leggett, 2012; Lucas, 2009; McCabe, 2005).

The fact that this study and the prior research have identified a real danger of students being unfairly excluded from study abroad opportunities because of existing mental health issues points to the importance of the timing and method of collecting information about students' mental health in order to encourage students to disclose relevant information. Mental health information should only be collected after students have been admitted to their study abroad programs, and to assuage students' fears that faculty instructors might treat them differently because of their mental health issues, information should be collected by a neutral third partying center.

Trained counseling professionals could then flag potential challenges that students might face while abroad and provide targeted support to both students and faculty instructors, specific to the mental health issues that may be relevant in particular courses. Counseling professionals might suggest specific interventions or accommodations (e.g., providing a detailed schedule to assuage mild anxiety) that would benefit all students without needing to identify a particular student with an existing mental health condition, again minimizing the risk of bias toward the student. Involving counseling center professionals could also take the burden off individual faculty members to do things like remind students to take their medication or check in periodically with a student with a potential serious mental health concern, which would enable the faculty instructors to focus on what they do best - teaching - rather than on addressing mental health issues.

Our findings also reflect the complexity of providing pre-trip training for faculty members regarding mental health issues that may arise abroad, and there are likely differences in what type of training is possible and desirable when it comes to mild and expected issues such as homesickness and stress compared to more serious issues 
like bipolar disorder and depression. Those who have written about the need for pre-trip training (e.g., Leggett, 2012; Morse et al., 2017; Prince et al., 2006) have included topics such as identifying mental health needs; identifying on-campus and in-country mental health resources; under- standing legal issues such as ADA, FERPA, and HIPAA; and explaining policies and procedures for responding to emergencies, including those related to mental health. These topics can provide a baseline of competencies that faculty instructors need to identify and respond to mental health issues, while not calling on instructors to serve as counselors, a role that they are not trained or prepared for. Some of our participants wanted this information and more, including more in- depth information on different types of mental health issues and skills and techniques to employ when addressing these issues. Other participants, however, did not want additional training. Faculty members often are required to attend a variety of trainings before teaching study abroad courses, so adding another mandatory training when serious mental health issues abroad are still relatively rare may not be practical or desired by faculty instructors. John also raised an important question of liability, fearing that with more specific training he would assuming additional liability for responding to mental health issues that could arise abroad.

For campus mental health professionals who might partner with education abroad offices in offering these types of pre-departure trainings, our findings point to some key issues to consider in weighing how much and what types of information these trainings might include. When it comes to the most serious mental health needs, more faculty training is likely not the answer, reflecting the concerns of some of our participants regarding the overall burden placed on faculty study abroad instructors and the potential liability that could come from this additional training.

For less serious issues, however, most of our participants responded through observation and conversation with students; this is where additional training could be most helpful and could relate to other roles that faculty members play in teaching study abroad courses. Issues of homesickness, culture shock, and mild anxiety related to travel to an unfamiliar location are likely far more common than serious mental health issues, and are also the issues that are less likely to show up on a pre-departure health screening questionnaire, as they are likely not related to any serious, existing mental health 
issue. As part of their broader training, faculty members might receive additional information about how to recognize serious mental health concerns that would require contacting mental health professionals in-country or on the home campus, and might also receive additional training about facilitating reflection and cultural mentoring that could also help them interact with students who are experiencing homesickness and mild anxiety related to travel and cultural adaptation.

While many faculty instructors might benefit from general training about mental health issues, as noted above, many of our participants raised concerns about the overall burden placed on faculty instructors in preparing for study abroad courses. This is again where student disclosure of mental health issues to counseling center staff prior to studying abroad could be important. In addition to giving counseling center staff the opportunity to support individual students while abroad, disclosure would also help staff provided targeted information and support to faculty instructors. This targeted training could provide the information that faculty instructors need for a particular course without burdening all faculty instructors with detailed mental health training that they are unlikely to need.

Although our findings do not clearly point to more faculty training being the answer, the ways in which some faculty participants addressed students' mental health needs abroad can provide insight into how college mental health professionals can best support faculty members when these situations arise. Having contact with trained psychologists and counselors on the home campus was important for participants when dealing with serious mental health concerns such as bipolar disorder, although it was noteworthy how seldom participants utilized mental health professionals on the home campus when issues arose. There is clearly an opening for campus mental health professionals to play a more active role in partnering with education abroad offices to directly support faculty instructors abroad. Some participants also noted the value in having parents' contact information. Although contacting parents would not always be appropriate, in certain circumstances and with a student's permission, parents can be a valuable source of support. Finally, education abroad professionals can help faculty members identify resources in-country (e.g., host families, in-country partners, and co-instructors) as part of their overall emergency preparedness planning. 


\section{Future research}

The findings from this study also point to a number of important directions for future research. First, although we can make some recommendations for encouraging disclosure based on our data from faculty instructors, more research is needed to identify the conditions that actually make students more likely to disclose significant mental health information prior to studying abroad. Second, more research is needed on the effectiveness of particular pre-trip training sessions for faculty instructors, both in general and specific to the topic of addressing student mental health needs abroad. As student disclosure and faculty preparation were two key themes in this study, we believe that future research in both of these areas is necessary in order to best support both students and faculty instructors abroad.

\section{Conclusion}

The increased enrollment of students with mental health needs in higher education in the United States (Prince, 2015), paired with increasing emphasis on study abroad participation (IIE, 2016) has led campus mental health professionals to consider how their services might extend to serve students with mental health needs who are studying abroad (e.g., Prince et al., 2006). When it comes to FLSTSA courses, the fastest growing sector of study abroad (IIE, 2016; Tuma, 2007), faculty instructors can play a key role in providing onthe-ground support for students experiencing mental health challenges. The findings from this study provide key insights into faculty instructors' experiences with mental health issues abroad, which college mental health professionals can use to better understand and support these instructors as they serve on the front lines of addressing students' mental health needs while they are away from campus. In particular, our findings point to keyways that college mental health professionals can partner with education abroad offices to provide effective pre-departure training and in-country support for faculty instructors. 
Disclosure - No potential conflict of interest was reported by the authors.

\section{References}

Adams, R., \& Reinig, M. (2017). Student application, selection, and acceptance. In L. Chieffo \& C. Spaeth (Eds.), The guide to successful short-term programs abroad (3rd ed., pp. 257-270). Washington, DC: NAFSA: Association of International Educators.

American College Health Association. (2018). American college health associationnational college health assessment II: Reference group executive summary fall 2018. Retrieved from https://www.acha.org/NCHA/ACHA-NCHA_Data/Publications and_Reports/NCHA/Data/Reports_ACHA-CHAIIc.aspx

Bathke, A., \& Kim, R. (2016). Keep calm and go abroad: The effect of learning abroad on student mental health. Frontiers: The Interdisciplinary Journal of Study Abroad, 27, 1-16.

Creswell, J. W. (2003). Research design: Qualitative, quantitative, and mixed methods approaches (2nd ed.). Thousand Oaks, CA: SAGE.

Creswell, J. W., \& Poth, C. N. (2018). Qualitative inquiry \& research design: Choosing among five approaches (4th ed.). Los Angeles, CA: SAGE.

Feldman Barr, T. (2013). Utilizing student affairs professionals to enhance student and faculty experiences and mitigate risk in short-term, faculty-led study abroad programs. Journal of International Education in Business, 6(2), 136-147. doi:10.1108/JIEB-05-2013-0019

Healthy Minds Network. (2019). Frequently asked questions about college student mental health data and statistics. Retrieved from https://hmn-live.isr.umich. edu/wp-content/uploads/2019/04/FAQs-about-Student-Mental-Health-Dataand-Statistics_FINAL.pdf

Heely, M. E. (2005). The contribution of international work and study experience to the professional life and practice of adult and higher education faculty (Unpublished doctoral dissertation). Columbia University, Teachers College, New York, NY.

Herbst, M. T. (2011). Building a faculty-lead study abroad program: From development to history pedagogy in Istanbul. History Teacher, 44(2), 209-226.

Holm-Hadulla, R. M., \& Koutsoukou-Argyraki, A. (2015). Mental health of students in a globalized world: Prevalence of complaints and disorders, methods and effectivity of counseling, structure of mental health services for students. Mental Health \& Prevention, 3 (1-2), 1-4. doi:10.1016/j.mhp.2015.04.003

Hunley, H. A. (2010). Students' functioning while studying abroad: The impact of psychological distress and loneliness. International Journal of Intercultural Relations, 34(4), 386-392. doi:10.1016/j.ijintrel.2009.08.005

Institute of International Education. (2015). Leading institutions by duration of study abroad and institution type, 2013/14. Open Doors Report on International 
Education Exchange. Retrieved from https://www.iie.org/Researchand-Insights/Open-Doors/Data/US-Study- Abroad/Leading-Institutions/

Leading-Institutions-by-Duration-and-Institutional-Type/2013-14

Institute of International Education. (2016). Open doors 2016 executive survey. Retrieved from https://www.iie.org/en/Why-IIE/ Announcements/2016-11-14-Open-Doors-Executive-Summary

Keese, J. R., \& O’Brien, J. (2011). Learn by going: Critical issues for faculty-led study-abroad programs. The California Geographer, 51, 3-24.

Leggett, K. (2012). Their baggage goes, too. International Educator, 2012(Suppl.), $11-17$.

Lucas, J. (2009). Over-stressed, overwhelmed, and over here: Resident directors and the challenges of student mental health abroad. Frontiers: The Interdisciplinary Journal of Study Abroad, 18, 187-215.

McCabe, L. (2005). Mental health and study abroad: Responding to the concern. International Educator, 14(6), 52-57.

Merriam, S. B. (2007). Qualitative research and case study applications in education. San Francisco, CA: Jossey-Bass.

Miles, M. B., Huberman, A. M., \& Saldaña, J. (2014). Qualitative data analysis: A methods sourcebook (3rd ed.). Los Angeles, CA: SAGE.

Morse, C. C., Spoltore, J. D., \& Galvinhill, P. (2017). College/university counseling centers supporting study away: Challenges and opportunities. Journal of College Student Psychotherapy, 31(4), 325-335. doi:10.1080/87568225.2017.131369o

Prince, J., DeRomana, I., Holvey-Bowles, J., \& Hopkins, S. (2006). Best practices in addressing mental health issues affecting education abroad participants. Washington, DC: NAFSA: Association of International Educators.

Prince, J. P. (2015). University student counseling and mental health in the United States: Trends and challenges. Mental Health \& Prevention, 3(1-2), 5-10. doi:10 $.1016 /$ j. mhp.2015.03.001

Rhodes, G. (2014). Risk management for study abroad programs: Issues and resources to inform program development, administration, and training. New Directions for Student Services, 2014(146), 41-50. doi:10.1002/ss.20089

Saldaña, J. (2016). The coding manual for qualitative researchers (3rd ed.). Thousand Oaks, CA: SAGE.

Scharman, J. S. (2002). The extended campus safety abroad. New Directions for Student Services, 2002(99), 69-76. doi:10.1002/ss.62

Stake, R. E. (2006). Multiple case study analysis. New York, NY: Guildford Press.

Tuma, K. (2007). Program models. In S. E. Spencer \& K. Tuma (Eds.), The guide to successful short-term programs abroad (2nd ed., pp. 41-45). Washington, DC: NAFSA: Association of International Educators. 